\title{
Performance Testing of Foldable Electric Powered Wheelchair
}

\author{
Raj Kumar Chaulagain ${ }^{*}, 1$, Gaurav Dahal ${ }^{1}$, Alkesh Nepal ${ }^{1}$, Amrit Tiwari' ${ }^{1}$, and Pramod Regmi ${ }^{1}$ \\ ${ }^{1}$ Department of Automobile and Mechanical Engineering, Thapathali Campus, Institute of Engineering, \\ Tribhuvan University, Thapathali, Kathmandu, Nepal \\ "Corresponding Email: rajkrc12@tcioe.edu.np
}

\begin{abstract}
This paper aims to design and test a foldable, lightweight wheelchair propelled by a pair of electric motors. Starting from literature review, the research team carried out the design and solid modeling of proposed wheelchair. Solidworks software was used to make the computer model. The wheelchair frame comprised of a chair like frame with two pairs of wheels on front and back. The defined electric wheelchair is completed with the coordination of manual and electric system. A pair of electric motor is fitted on wheels at backside which are controlled by the electronic controller powered by the battery. The folding mechanism developed on the wheelchair was aimed for ease of transport and storage. The frame material was selected to be aluminum alloy. Lithium ion battery and geared electric motors were used in the prototype and motion control was done by joystick. Locking mechanism was used for frame locking during operation. The prototype was subjected to different tests. The unfolded dimensions of wheelchair were $850 \mathrm{~mm} \times 620 \mathrm{~mm} \times 1400 \mathrm{~mm}\left(0.738 \mathrm{~m}^{3}\right)$ and whereas the folded dimensions were $1100 \mathrm{~mm} \times 620 \mathrm{~mm} \times 520 \mathrm{~mm}\left(0.354 \mathrm{~m}^{3}\right)$ that resulted $52.03 \%$ reduction in volume. The mass of wheelchair was measured to be $22 \mathrm{~kg}$. The tested data of wheelchair was found to be $10 \mathrm{~km}$ approximately.
\end{abstract}

Keywords: Foldable, Solidworks Model, Stability Test, Volume, Wheelchair

\section{INTRODUCTION}

A wheelchair is a chair with wheels, used when walking is difficult or impossible due to illness, injury or disability. There are wide varieties of wheelchair according to needs as indoor or outdoor, sports or medical, etc. In terms of the power used for propelling, it can be classified as manual and powered wheelchairs. Motorized or powered wheelchair is a wheelchair that is propelled by means of an electric motor [1]. The energy required to propel the wheelchair is chemical energy from the battery. An electric system consisting of input, controller, battery, microchip, motor, etc. are integrated in wheelchair. Several studies have shown that both children and adults benefit substantially from access to a means of independent mobility, including power wheelchairs, manual wheelchairs, scooters, and walkers [2]. Motorized wheelchairs are useful for those unable to propel a manual wheelchair or who may need to 
use a wheelchair for distances or over areas which would be fatiguing in a manual wheelchair. Not only physically challenged people even this can be utilized by other people for short travel within a limited boundary like as inside a university or any working areas [3]. Motorized wheelchairs are designed for indoors, outdoors or even both. Folding ability of the wheelchair make it easier for the transportation and compact design occupies less space.

In 1655, Stephan Farffler, a 22-year-old paraplegic watchmaker, built the world's first self-propelling chair on a three-wheel chassis using a system of cranks and cogwheels. However, the device had an appearance of a hand bike more than a wheelchair since the design included hand cranks mounted at the front wheel [4]. An electrically propelled tricycle was developed by the R.A. Harding Company in England in the 1930s. The electric-powered wheelchair was invented by George Klein who worked for the National Research Council of Canada, to assist injured veterans after World War II [5].

\section{PROBLEM STATEMENT}

Manual wheelchairs are troublesome to operate for differently able and weak people [6]. Non ambulatory children lack access to the wealth of stimuli afforded self-ambulating children. The lack of exploration and control often produces a cycle of deprivation and reduced motivation that leads to learned helplessness [7]. In case of Nepal, till date, electric wheelchairs are imported from abroad and have been time and cost consuming. Also most of them are difficult to pull over the lane or ground while folded.

So, this research was aimed to decrease the height resulting in decrease of overall volume of the wheelchair and uses the local resources available for the complete production. It was expected for ease of transportation and storage through the help of a locking mechanism.

\section{RESEARCH OBJECTIVE}

The major objective of this research was to design and test the foldable electric powered wheelchair. The specific objectives are as follows:

- To design the wheelchair frame and allocate the position of components.

- To select the lock and folding mechanism.

- To fabricate the wheelchair including all the components.

- To test the performance of the wheelchair as per standard guidelines. 


\section{RESEARCH METHODOLOGY}

Followings were the research activities conducted sequentially for completion of the task.
a. Problem Detailing
b. Literature Review
c. Concept Development
d. Material Availability
e. Design Calculation
f. Computer Aided Drafting
g. Fabrication
h. Performance Testing
i. $\quad$ Final Reporting

\section{DESIGN SUMMARY}

\subsection{MOTOR}

Table 1: Motor power calculation

\begin{tabular}{|l|l|l|c|}
\hline S.N. & Term & Formula** & Value \\
\hline 1 & Rolling Resistance & $\mathrm{R}_{\mathrm{r}}=\mu \times \mathrm{m} \times \mathrm{g} \times \cos \Theta$ & $13.53 \mathrm{~N}$ \\
\hline 2 & De-Alembert's Force: & $\mathrm{F}_{\mathrm{d}}=\mathrm{m} \times \mathrm{a}$ & $23.8 \mathrm{~N}$ \\
\hline 3 & Component of weight down the incline & $\left(\mathrm{F}_{\mathrm{w}}\right)=\mathrm{m} \times \mathrm{g} \times \sin 10^{\circ}$ & $238.49 \mathrm{~N}$ \\
\hline 4 & Aerodynamic Force & $\left(\mathrm{F}_{\mathrm{a}}\right)=1 / 2 \times \rho \times \mathrm{A} \times \mathrm{C} \times\left(\mathrm{V}_{\mathrm{r}}\right)^{2}$ & $24.22 \mathrm{~N}$ \\
\hline 5 & Total force & $\mathrm{F}_{\mathrm{t}}=\mathrm{R}_{\mathrm{r}}+\mathrm{F}_{\mathrm{d}}+\mathrm{F}_{\mathrm{w}}+\mathrm{F}_{\mathrm{a}}$ & $300.04 \mathrm{~N}$ \\
\hline 6 & Largest torque requirement & $\mathrm{F}_{\mathrm{t}} \times \mathrm{r}$ & $45.006 \mathrm{Nm}$ \\
\hline 7 & Power requirement $(500 \mathrm{~W}$ selected $)$ & $\mathrm{F}_{\mathrm{t}} \times \mathrm{v}$ & 501.07 watt \\
\hline
\end{tabular}

\subsection{BATTERY}

A motor with 250 Watts was selected to draw 8 A current at maximum [8]. So, supplying current to both motors being 250 watts each, the battery must provide 16A at most. The average speed of wheelchair is $6 \mathrm{Kmph}$ and average travel distance of a wheelchair in a day is $8 \mathrm{Km}$ travel distance in a day with full charge. The time of use of wheelchair is $8 / 6=1.34 \mathrm{hrs}$. So, the capacity of battery is $=16 \times 1.34=20.8$ $\mathrm{Ah}$ (20Ah is selected) 


\subsection{WHEELCHAIR FRAME}

\begin{tabular}{|c|c|c|c|}
\hline S.N. & Terms & Formula [9] & Value \\
\hline 1 & Factor of Safety & $\mathrm{fs}=\frac{\text { ultimate load }}{\text { allowable load }}$ & 1.5 \\
\hline 2 & $\begin{array}{l}\text { Total Stress on Pipe for Eccentric } \\
\text { Axial Loading }\end{array}$ & $\begin{array}{l}\left(\sigma_{x}\right)=\left(\sigma_{x}\right)_{\text {centric }}+\left(\sigma_{x}\right)_{\text {bending }} \\
\text { or, } \sigma_{x}=\frac{P}{A}+\frac{M y}{I} \\
\text { solving for diameters }\end{array}$ & $d_{0} \geq 0.0120911 \mathrm{~m}$ \\
\hline 3 & Critical Load on Pipes for Buckling & $\begin{array}{l}\qquad P_{c r}=\frac{\pi E I}{L^{2}} \\
\text { solving for diameters }\end{array}$ & $d_{0} \geq 0.015 m$ \\
\hline 4 & Average Shear Stress on Joint Pins & $\begin{array}{r}\text { tave }=\frac{\mathrm{P}}{\mathrm{A}} \\
\text { solving for diameter }\end{array}$ & $d=0.00108 \mathrm{~m}$ \\
\hline 5 & Average Bearing Stress on Joint pins & $\begin{array}{c}\sigma b=\frac{P}{A} \\
\text { solving for diameter }\end{array}$ & $d=6.18 \times 10^{-6} \mathrm{~m}$ \\
\hline 6 & Bending Stress on Joint Pins & $\begin{array}{l}\qquad \frac{I}{C}=\frac{M_{\max }}{\sigma_{\text {all }}} \\
\text { solving for diameter }\end{array}$ & $d=5.27 \times 10^{-3} \mathrm{~m}$ \\
\hline 7 & Design of Bolt for Shear Stress & $\begin{array}{r}\sigma a l l=\frac{\mathrm{P}}{\mathrm{A}} \\
\text { solving for diameter }\end{array}$ & $d=7.44 \times 10^{-4} \mathrm{~m}$ \\
\hline 8 & Design of Bolt for Bearing Stress & $\begin{array}{c}\sigma \mathrm{b}=\frac{\mathrm{P}}{\mathrm{td}} \\
\text { solving for diameter }\end{array}$ & $d=4.83 \times 10^{-6} \mathrm{~m}$ \\
\hline 9 & Design of Bolt for Bending & $\begin{array}{l}\qquad \frac{I}{C}=\frac{M_{\max }}{\sigma_{\text {all }}} \\
\text { solving for diameter }\end{array}$ & $d=3.81 \times 10^{-3} \mathrm{~m}$ \\
\hline
\end{tabular}

\subsection{STRENGTH ANALYSIS OF FOLDING LOCK MECHANISM}

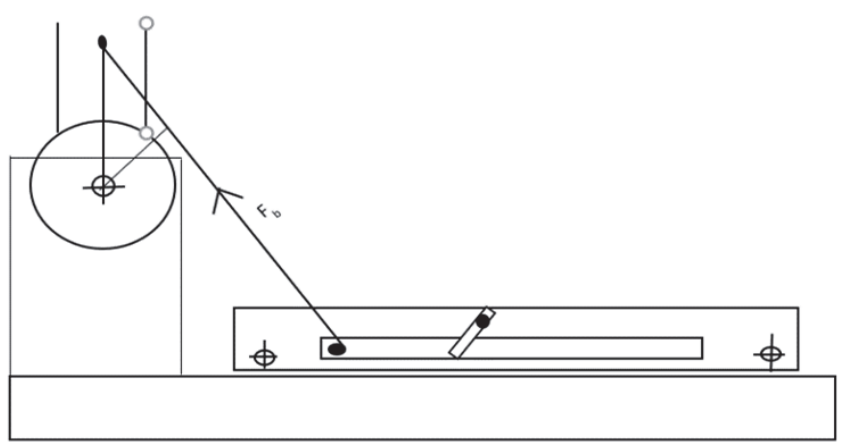

Figure 1: Analytical Calculation of Working Mechanism of Folding Lock 
The folding lock was tested for strength as below:

Moment about centre $=800 \times 0.2 \mathrm{Nm}=160 \mathrm{Nm}$

$80 \mathrm{Nm}$ moment is supplied by each side's lock system in order to lock the wheelchair folding.

$\mathrm{R}_{\mathrm{b}}=0.065 \times \sin 45^{\circ}=0.05 \mathrm{~m}$

$$
\mathrm{F}_{\mathrm{b}} \times \mathrm{R}_{\mathrm{b}}=80 \quad \text { or, } \mathrm{F}_{\mathrm{b}}=\frac{80}{0.05}=1600 \mathrm{~N}
$$

Lock material's dimension is $\mathrm{l} \times \mathrm{b} \times \mathrm{h}$ from turning point to the base of it.

The shear average strength withstood by it is

$$
\sigma_{\mathrm{s}}=\frac{\mathrm{F}_{\mathrm{b}}}{\mathrm{l} \times \mathrm{b}}=\frac{1600}{0.03 \times 0.02}=2.7 \times 10^{7 \mathrm{~N}} / \mathrm{m}^{2}
$$

Bearing, $\sigma_{\mathrm{b}}=\frac{\mathrm{F}_{\mathrm{b}}}{0.008 \times \mathrm{b}}=\frac{1600}{0.008 \times 0.02}=1 \times 10^{7 \mathrm{~N}} / \mathrm{m}^{2}$

The bearing and shear stress withstood by bolt holding the lock material is,

$$
\begin{gathered}
\sigma_{\mathrm{b}}=\frac{\mathrm{F}_{\mathrm{b}}}{0.008 \times \mathrm{b}}=\frac{1600}{0.008 \times 0.02}=1 \times 10^{7 \mathrm{~N}} / \mathrm{m}^{2} \\
\sigma_{\mathrm{s}}=\frac{\mathrm{F}_{\mathrm{b}}}{\frac{\pi \times(0.008)^{2}}{4}}=\frac{1600 \times 4}{\pi \times 0.008^{2}}=3.2 \times 10^{7} \mathrm{~N} / \mathrm{m}^{2}
\end{gathered}
$$

Comparing the above data with the Mechanical Properties of the materials [10], it is concluded that lock material is strong enough to hold the folding while operation

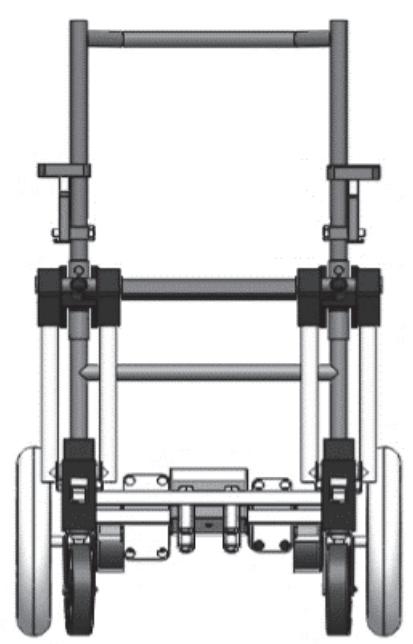

Figure 2: Unfolded Front View of the Wheelchair

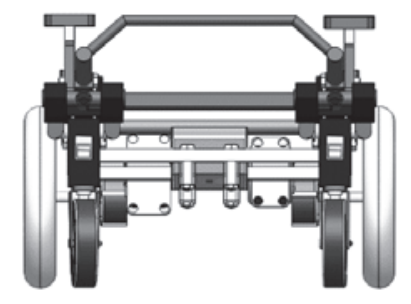

Figure 3: Folded Front View of the Wheelchair 


\section{PERFORMANCE TEST}

\subsection{STATIC STABILITY TEST}

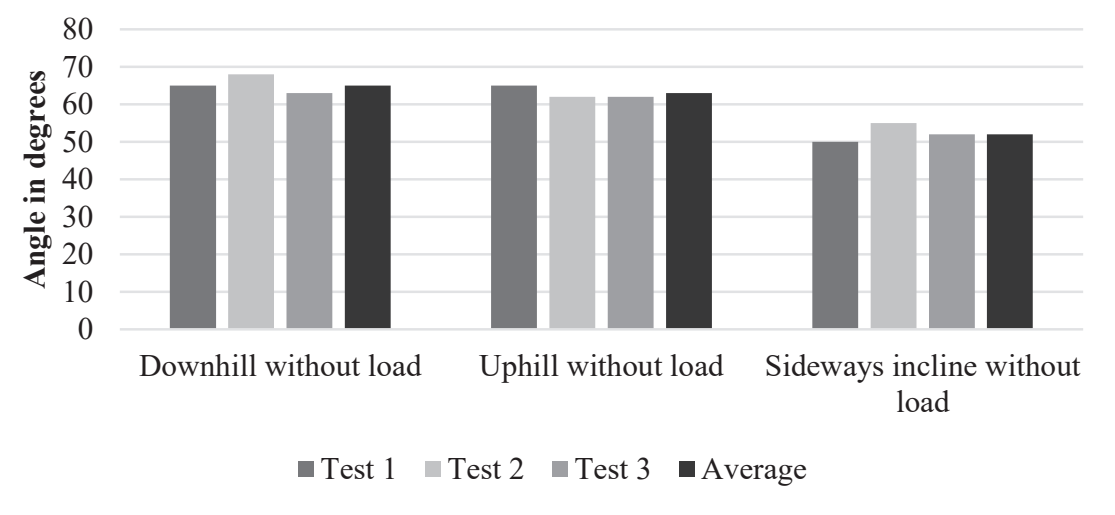

Figure 4: Static Stability Test Chart

\subsection{DETERMINATION OF ENERGY CONSUMPTION OF ELECTRIC WHEELCHAIR}

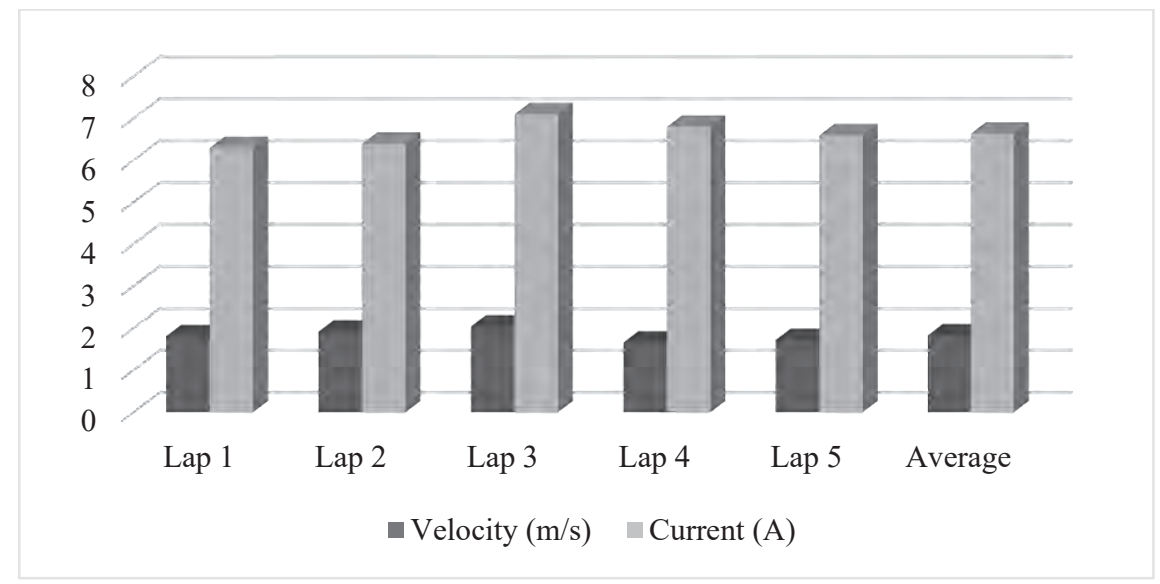

Figure 5: Comparison of Current and Velocity for each 20m Lap distance

The average value of velocity was found to be $1.83 \mathrm{~m} / \mathrm{s}$ and Average consumption of current on $20 \mathrm{~m}$ distance was $6.64 \mathrm{~A}$.

Rated Ampere hours of battery $=20 \mathrm{Ah}$

Total Distance $=100 \mathrm{~m}$

Total Time $=54.8 \mathrm{sec}$

From calculation, theoretical range of travelling $=9.84 \mathrm{~km}$ 


\subsection{MAXIMUM SPEED AND STOPPING DISTANCE}

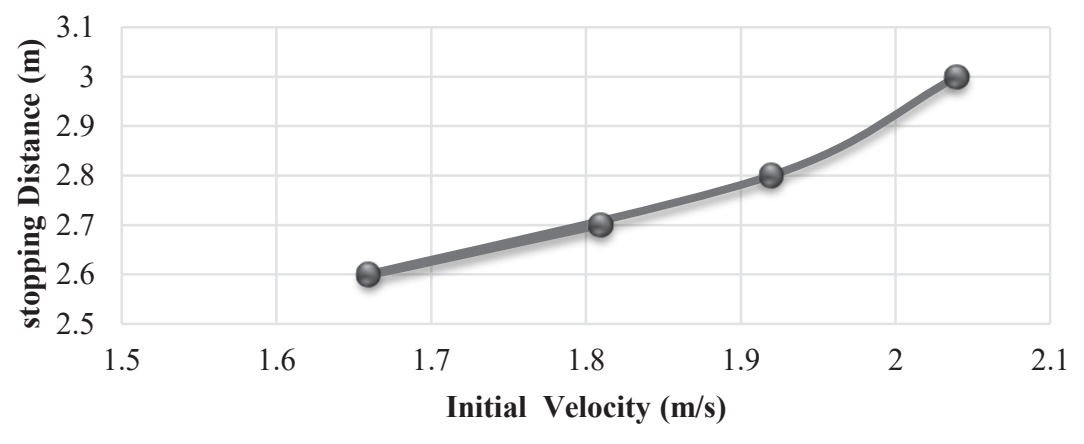

Figure 6: Stopping Distance with respect to Initial Velocity

\subsection{DIMENSION TEST}

\begin{tabular}{|l|l|c|r|r|r|l|}
\hline \multirow{2}{*}{ S. $\mathbf{N}}$. & \multicolumn{1}{|c|}{$\begin{array}{c}\text { Wheelchair } \\
\text { condition }\end{array}$} & $\begin{array}{c}\text { Length } \\
\mathbf{( m )}\end{array}$ & $\begin{array}{c}\text { Breadth } \\
\mathbf{( m )}\end{array}$ & $\begin{array}{c}\text { Height } \\
\mathbf{( m )}\end{array}$ & $\begin{array}{c}\text { Total } \\
\left.\text { volume } \mathbf{( m}^{\mathbf{3}}\right)\end{array}$ & \multicolumn{1}{|c|}{ Remarks } \\
\hline 1 & Unfolded & 0.85 & 6.20 & 1.40 & 0.738 & $52.03 \%$ volume \\
& Folded & 1.10 & 6.20 & 0.52 & 0.354 & reduced \\
\hline
\end{tabular}

\subsection{OBSTACLE CLIMBING TEST}

The Obstacle climbing test was carried out and it was concluded that the obstacle could not climb obstacle of height more than $3 \mathrm{~cm}$.

\section{CONCLUSION}

Referring to the major objective of this research, the Foldable Electric Powered Wheelchair was designed, fabricated and tested. During this, following conclusions were drawn:

1. The wheelchair frame was designed and modeled in Solidworks Software.

2. Four-bar folding mechanism and folding-shelf locking mechanism were used which resulted in $52.03 \%$ volume reduction.

3. The fabrication of designed wheelchair was done and different components were fitted to form up a fully functional wheelchair.

4. Maximum stability was obtained on downhill condition whereas the theoretical range for wheelchair was calculated to be $9.84 \mathrm{Km}$.

\section{RECOMMENDATIONS}

The following recommendations were drawn for the future improvement:

a. Use of motors with solenoid brakes can be introduced in order to overcome the braking limitations.

b. Suspension systems can also be used for shock absorption and comfort.

c. Wheels of larger radius can be used in order to climb obstacles of higher height. 


\section{ACKNOWLEDGEMENT}

Everyone who helped in completion of this research are thanked heartedly whereas followings are specially acknowledged:

- Department of Automobile and Mechanical Engineering, Thapathali Campus, Thapathali for support throughout the project.

- Infinity Lab, Balaju School of Engineering and Technology, Balaju for providing technical support.(Phone No:+977-1-4491278)

- $\quad$ Future Lab, Kupandole for helping in the context of electronic control.(Phone No: 981238573, Email Address: sanam_shakya@futurelab-nepal.com)

\section{REFERENCES}

[1] Cooper, R. A., Widman, L. M., Jones, D. K., Robertson, R. N., \&Ster, J. F. (2000). Force Sensing Control for Electric Powered Wheelchairs, 8(1), 112-117.

[2] Kollman J, Lankenau A, Buhlmeier A, Krieg-Bruckner B, Röfer T. Navigation of a kinematically restricted wheelchair by the parti-game algorithm. In: Spatial reasoning in mobile robots and animals. Sharkey N, Nehmzow U, editors. Proceedings of the 1997 AISB Workshop on Robot Navigation; 1997 Apr 7-8;Manchester, UK. Manchester (UK): Manchester University; 1997. p. $35-44$.

[3] Cooper, R. A., Spaeth, D. M., Jones, D. K., Boninger, M. L., Fitzgerald, S. G., \& Guo, S. (2002). Comparison of virtual and real electric powered wheelchair driving using a position sensing joystick and an isometric joystick, 24, 703-708.

[4] Crompton, S. (2015). Manual Wheelchairs. The Carers Guide, 159-160. https://doi.org/10.1007/978-1-349-13869-2_70

[5] Mclaurin, C. A., \& Axelson, P. (1987). Future Developments Wheelchair Standards : An Overview. The Canadian Paraplejic Association, 100-103.

[6] Gignac MA, Cotta C, Badley EM. Adaptation to chronic illness and disability and its relationship to perceptions of independence and dependence. J Gerontol B Psychol Sci Soc Sci. 2000;55(6):36272.

[7] Davies, A., De Souza, L. H., \& Frank, A. O. (2003). Changes in the quality of life in severely disabled people following provision of powered indoor/outdoor chairs. Disable Rehabil, 25(6), 286290.

[8] Warren, C. G. (1990). Powered mobility and its implications. J Rehabil Res Dev Clin Suppl(2), 7485.

[9] Beer,P.,Ferdinand,Jr.,Johnston,Russell,Dewolf,T.,John,Mazurek,F.,David(2012).Mechanics of Materials, $6^{\text {th }}$ Edition.

[10]Ashraf, A. (2015). Mechanical Properties of Materials Mechanical Properties of Aluminum, stainless, (December 2014). https://doi.org/10.13140/2.1.4179.5362 